\title{
Matriz morfológica e biomimética: geração de alternativas em design
}

\section{Morphological matrix and biomimetics: alternatives generation in design}

KANDA, Gisele Brandão

Universidade de São Paulo - USP I gisele.kanda@outlook.com

SOUZA, Rejane de Oliveira

Universidade Estadual Paulista - UNESPI rejane_os@yahoo.com.br

HELD, Maria Sílvia Barros de

Universidade de São Paulo - USP I silviaheld@usp.br

\begin{abstract}
Resumo
Este artigo discute as possibilidades de uma nova técnica para orientar a concepção de um produto. Foram combinadas a matriz morfológica e a bioinspiração para fornecer um escopo de discussões para o brainstorm que antecede a fase de desenvolvimento do produto. Como exemplo de aplicação, utilizou-se a técnica para a concepção de um maiô esportivo de natação. O projeto foi bioinspirado na superfície corporal, na anatomia e no habitat dos tubarões.
\end{abstract}

Palavras-chave: Matriz morfológica. Bioinspiração. Desenvolvimento de produto. Design.

\section{Abstract}

This paper discusses the possibilities of a new technique to guide product development. The morphological matrix and the bioinspiration were combined in order to provide resources during the brainstorm stage, which precedes the product development itself. The application of this combined matrix was used in the development of a swimsuit. The project was bioinspired by sharks: body surface, anatomy and habitat.

Keywords: Morphological matrix. Bioinspiration. Product development. Design. 


\section{INTRODUC̣ÃO}

O tema de desenvolvimento do produto, nas teorias do design, apresenta muitos desafios, como alcançar diversas maneiras inovadoras e funcionais para guiar um designer no desenvolvimento de novos produtos. Um dos pontos mais desafiadores, possivelmente, seja o processo criativo de concepção.

Muitas técnicas focam em abordagens sistemáticas que auxiliam os designers durante esse processo, segundo Cross (2004) alguns alunos de design tendem a ser resistentes ao aplicar métodos mais sistemáticos na fase inicial do projeto. O autor afirma que os projetos, quando desde o início são estruturados, geralmente possuem uma melhor elaboração e apontam uma relação positiva entre a quantidade e a qualidade dos trabalhos apresentados pelos alunos. Adicionalmente, para Yang (2003), é fundamental no início do planejamento gerar o maior número de ideias (brainstorming), relacionar e registrar as que foram desenvolvidas inicialmente e posteriormente durante a execução do projeto. E principalmente esboçar o mesmo protótipo desde o início revisando os resultados e experiências obtidas.

Segundo Geschka (1983) o planejamento e o desenvolvimento do projeto reúnem uma série de elementos que demandam soluções criativas. Para o autor ao estruturar esses elementos é possível avaliar e inserir as ideias que forem mais promissoras, desta maneira os problemas que forem encontrados no transcorrer do projeto podem ser solucionados por meio de experiências técnicas, pessoais e talento, mas também podem ser solucionados de forma sistemática usando técnicas criativas.

Neste artigo é apresentada uma nova técnica para o brainstorm que antecede a fase de desenvolvimento de produto: um método que combina a matriz morfológica e a biomimética. $\mathrm{O}$ uso dessas técnicas juntas permite novas combinações de aplicação no desenvolvimento do produto.

Como exemplo prático, este artigo trabalhará na concepção de um maiô feminino de natação para atletas amadores de forma a ilustrar a técnica proposta. Nas próximas seções será descrita e ilustrada a técnica proposta, revisando conceitos da biomimética e a aplicação da matriz morfológica.

\section{DESIGN E A NATUREZA}

A natureza que se vê hoje é a consequência da evolução constante e busca pela própria sobrevivência. Os mecanismos que permitem a ela se adaptar a cada necessidade imposta pelo meio trazem para os seres humanos os segredos da eficiência e longevidade (PODBORSCHI, 2005). A 
busca por conhecimento por meio da natureza visa usufruir de um conteúdo de informações acumuladas durante bilhões de anos. Essas informações são representadas pela grande diversidade biológica existente e os seus processos de evolução apresentados pela história (PAWLYN, 2011, p. 2).

Não são pacíficos entre os autores os termos utilizados para nomear a busca da compreensão de algo através do olhar da natureza. Assim, para tornar mais fácil o entendimento desse campo de estudo foi criada pela International Organization for Standardization a norma ISO/TC 266 Biomimetics, contendo a norma ISO 18458:2015 Biomimetics - Terminology, concepts and methodology que apresenta algumas terminologias relacionadas a compreensão da natureza como inspiração (TERRIER; GLAUS; RAUFFLET, 2017).

A bioinspiração ou bioinspiration significa observar os sistemas biológicos como fonte de inspiração, com aplicação na criatividade, na inovação e no design (TERRIER; GLAUS; RAUFFLET, 2017).

A palavra biomimética vem do grego bios: vida, e mimesis: imitação. A biomimética é a ciência que utiliza os padrões encontrados na natureza para solucionar os problemas humanos por meio dos processos biológicos seja por meio da imitação ou como fonte de inspiração para a construção de um modelo (BENYUS 2003, p. 08). A biomimética trata de maneira interdisciplinar os sistemas biológicos, relacionando as estruturas, os mecanismos de funcionamento, os processos e as leis gerais para que esse conhecimento possa ser essencialmente aprimorado com a intenção de criar um modelo e levar para outros campos como uma solução aplicável (INTERNATIONAL ORGANIZATION FOR STANDARDIZATION, 2015).

A ISO 18458:2015 apresenta nomenclaturas que são originariamente cunhadas na língua inglesa. Os termos biomimetics e biomimicry são equivalentes aos termos biomimética ou biomimetismo em português. Os dois termos, segundo Pawlyn (2011, p. 2), apenas diferenciam-se em um aspecto: o biomimicry tem o objetivo de desenvolver soluções sustentáveis que envolvam os aspectos sociais, ambientais e econômicos.

Segundo Podborschi e Vaculenco (2005) em 1960 Jack Steele criou o termo bionics para nomear as pesquisas que envolviam os sistemas naturais e artificiais. A norma internacional determina que a biônica seja a análise de como os mecanismos biológicos dos seres vivos trabalham e como podem ser incorporados artificialmente nas tecnologias produzidas pelo homem com o objetivo de aumentar seu potencial, substituir funções ou copiar (INTERNATIONAL ORGANIZATION FOR STANDARDIZATION, 2015).

Sarkar et al. (2009) desenvolveram uma estrutura de tecido baseada na biomimética das raízes de algumas plantas, na qual foram testados vários tipos de fibras/fios que poderiam auxiliar no transporte da água. 
Colin Dawson pesquisouem1997 o mecanismo de abertura efechamento de uma pinha. Pesquisadores da Universidade de Bath desenvolveram um protótipo têxtil baseado no trabalho de Dawson que aplica o princípio a um fio capaz de aumentar a porosidade de uma estrutura têxtil em condições úmidas e reduzir a permeabilidade quando seco (WILLIAMS, 2009).

Hoefnagels et al. (2007) utilizaram como modelo natural a rugosidade encontrada nas folhas de lótus (Nelumbo nucifera), estas estruturas e a baixa energia de superfície de contato permitem que suas folhas escoem a água acumulada da sua superfície. A partir desta observação foi desenvolvido o experimento no qual utilizou-se tecido de algodão, originalmente hidrofílico, inseriram-se sílica e o polidimetilsiloxano com o objetivo de proprocionar mais rugosidade nas fibras, criando assim uma característica hidrofóbica ao têxtil.

A Teijin Fibre Corporation criou a Morphotex $\mathrm{TM}^{\circledR}$, baseada no design da asa da borboleta do gênero Morpho, encontrada na América do Sul. Os pesquisadores criaram uma fibra feita de sessenta e uma camadas alternadas de nylon e poliéster capazes de produzir cores básicas como azul, verde e vermelho sem o uso de pigmentos (VANJIWALE; RAMAKRISHNAN, 2009).

\section{MATRIZ MORFOLÓGICA}

A análise morfológica foi desenvolvida pelo cientista espacial suíço e astrofísico Fritz Zwicky no final década de 1940 no Instituto de Tecnologia da Califórnia (Caltech) (RITCHEY, 2006). Zwicky (1969 apud RITCHEY, 2006, p. 794) apresentou uma maneira de organizar e sistematizar uma pesquisa morfológica que envolvesse vários eixos temáticos, de maneira que pudesse ser possível misturar conceitos diferentes e que fizessem parte de uma mesma ideia central.

A técnica possibilita organizar e analisar as combinações dos elementos que constituem problemas multidimensionais, ou seja, a partir de um problema complexo é selecionado os elementos que o compõem, repartindo-o em problemas mais simples, tratando individualmente cada subproblema (PLENTZ, 2011).

Segundo Ostertag, Ostertagová e Huňady (2012) a matriz morfológica é disposta em forma de tabela. As linhas agrupam as características gerais ou os elementos mais simples que devem ser integradas no objeto ou na pesquisa e as colunas agrupam as possibilidades com que se consegue trabalhar, de maneira que torne ambas, linhas e colunas, relacionáveis. 
Desde a sua criação, a matriz morfológica foi modificada para atender às diversas necessidades, geralmente ela é usada em projetos de desenvolvimento de produto e na resolução de problemas multidimensionais (PEREIRA et al., 2014).

Loureiro et al. (2013) reconheceram que as máquinas tradicionalmente usadas que realizavam a colheita do café apresentavam restrições quando operavam em terrenos montanhosos. A partir desta percepção foi criado um mecanismo que pudesse romper esta barreira, para isso uma série de etapas foram desenvolvidas na pesquisa e uma delas foi a elaboração de uma matriz morfológica que relacionava a subfunção com a solução conforme a figura 1 demonstra.

Figura 1. Matriz morfológica no desenvolvimento de colhedoras de café.

\begin{tabular}{|c|c|c|c|c|c|c|}
\hline \multicolumn{2}{|c|}{ Sub-funcöes } & 1 & 2 & 3 & 4 & 5 \\
\hline 1 & $\begin{array}{c}\text { Levantar } \\
\text { Saia }\end{array}$ & Dedos Retrieis & $\begin{array}{c}\text { Plataforma em } \\
\text { eurha }\end{array}$ & Lamina niveladoesa & $\cdots$ & $\cdots$ \\
\hline 2 & $\begin{array}{l}\text { Vedar } \\
\text { Tronco }\end{array}$ & Laminas Retrateis & $\begin{array}{c}\text { Vedaçắo por } \\
\text { velicro }\end{array}$ & $\begin{array}{c}\text { Vedaçă por por } \\
\text { cerdas }\end{array}$ & $\begin{array}{c}\text { Vedaç3̄o cadmera } \\
\text { ar }\end{array}$ & $\cdots$ \\
\hline 3 & $\begin{array}{l}\text { Transporte } \\
\text { Horizontal }\end{array}$ & $\begin{array}{c}\text { Trasportader de } \\
\text { conrectes }\end{array}$ & $\begin{array}{l}\text { ortador de } \\
\text { meiss }\end{array}$ & $\operatorname{sem}$ fom & $\begin{array}{c}\text { Transportador de } \\
\text { cxaccos }\end{array}$ & $\cdots$ \\
\hline 4 & $\begin{array}{c}\text { Transporte } \\
\text { Vertical }\end{array}$ & & & - & $\cdots$ & $\cdots$ \\
\hline 5 & $\begin{array}{c}\text { Separar } \\
\text { Impurezas }\end{array}$ & & $\begin{array}{l}\text { Sepurados } \\
\text { poeumitico }\end{array}$ & Cilindro Bateder & Pestus & $\cdots$ \\
\hline 6 & $\begin{array}{c}\text { Controlar } \\
\text { Velocidade }\end{array}$ & $\begin{array}{l}\text { laverior de } \\
\text { Freguencis }\end{array}$ & 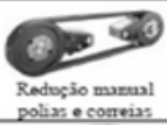 & $\begin{array}{l}\text { Reducbo munval } \\
\text { por eapresigens }\end{array}$ & $\cdots$ & $\cdots$ \\
\hline 7 & $\begin{array}{l}\text { Converter } \\
\text { Energia }\end{array}$ & Gerador i Diesel & Gerador & Gendor is Biodiesel & Gendor i Biogis & $\cdots$ \\
\hline 8 & $\begin{array}{l}\text { Transmitir } \\
\text { Potência }\end{array}$ & Enpreasgens & Poliase & Eixo Cadus & $\cdots$ & $\cdots$ \\
\hline 9 & $\begin{array}{l}\text { Armazenar } \\
\text { Frutos }\end{array}$ & Gravelesuo & $\begin{array}{c}\text { Trnisportador } \\
\text { Secundivio }\end{array}$ & ‥ & $\cdots$ & $\cdots$ \\
\hline
\end{tabular}

Fonte: Loureiro et al. (2013).

Pereira et al. (2014) usaram a matriz para o solucionar um problema. Eles desenvolveram um produto que permitisse transportar uma criança, de maneira prática, por um adulto. Para isso os autores elaboraram uma matriz com a fusão entre um patinete e um berço, como mostra a figura 2 . 
KANDA, Gisele Brandão; SOUZA, Rejane de Oliveira; HELD, Maria Sílvia Barros de

Figura 2. Matriz morfológica para a criação de um carrinho para crianças.

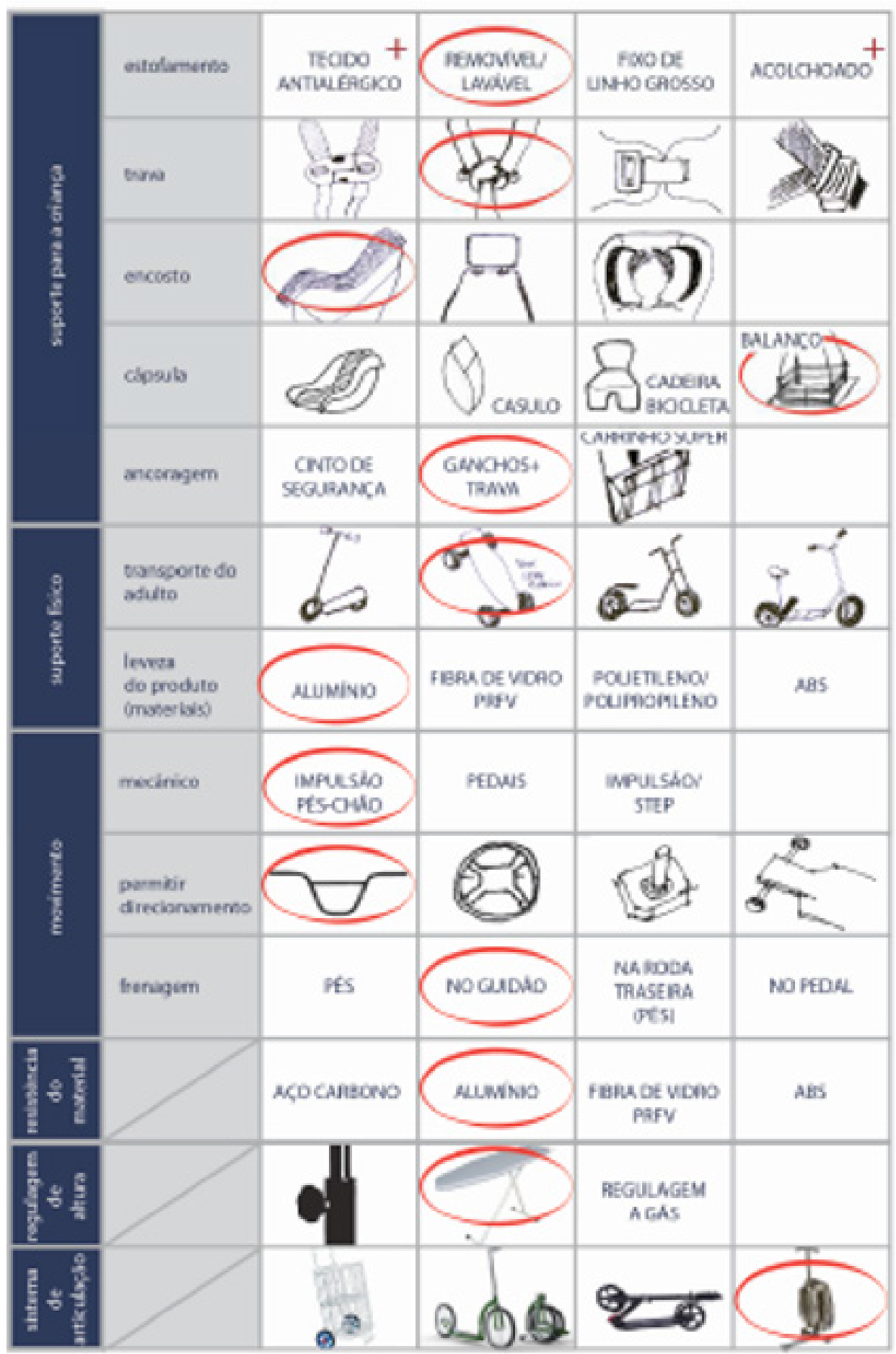

Fonte: Pereira et al. (2014).

\section{MATRIZ MORFOLÓGICA BIOINSPIRADA}

Comumente, a matriz morfológica tem sido apresentada na literatura acadêmica como processo de geração de ideias para o desenvolvimento de produtos. Contudo, guiar a concepção de um produto exclusivamente pela matriz morfológica em sua forma original pode colocar de lado aspectos que, 
embora menos tangíveis ou abstratos, são importantes para se atingir um objetivo funcional com o projeto. Na área têxtil, por exemplo, no segmento de têxteis esportivos, por vezes, um designer precisa pensar em aspectos como conforto, transporte de umidade, aerodinâmica, atrito etc. Tais características podem ser obtidas não apenas orientando a um único atributo do têxtil, mas, geralmente, são resultados de muitos deles - conforto, por exemplo, pode ser obtido tanto na seleção da fibra, quanto na construção do fio, na produção do tecido, no beneficiamento, etc.

Quando o conjunto de atributos menos tangíveis é inspirado em um mesmo tema, ele pode ser reunido em uma dimensão e acrescentado à matriz morfológica guiando a seleção das opções - a escolha de fios com propriedade de baixa absorção de umidade, por exemplo, pode orientar na listagem dos fios sintéticos.

A partir desse pressuposto, apresenta-se aqui uma proposta de utilização da matriz morfológica bioinspirada para a construção de um maiô de natação esportivo. Em muitos casos, a natureza já solucionou certos problemas que são comuns aos atletas como velocidade, aerodinâmica, proteção, etc. Buscar traduzir essas respostas adaptativas naturais em projetos têxteis podem orientar o designer na concepção de projetos que resultam em maior performance. Na figura 3 acrescenta-se à matriz morfológica tradicionalmente utilizada uma nova dimensão de análise.

Figura 3. Matriz morfológica tradicional e nova proposta (respectivamente).

\begin{tabular}{|c|c|c|c|c|}
\hline ब) & $\begin{array}{c}\text { Variável } \\
1\end{array}$ & Opção 1 & Opção 2 & Opção 3 \\
\hline एँ & $\begin{array}{c}\text { Variável } \\
2\end{array}$ & Opção 1 & Opção 2 & Opção 3 \\
\hline ن & $\begin{array}{c}\text { Variável } \\
3\end{array}$ & Opção 1 & Opção 2 & \begin{tabular}{|l} 
\\
Opção 3
\end{tabular} \\
\hline
\end{tabular}

\begin{tabular}{|c|c|c|c|c|}
\hline & \multicolumn{3}{|c|}{ Características Bioinspiradas } \\
\hline & & $\begin{array}{c}\text { Variável } \\
1\end{array}$ & $\begin{array}{c}\text { Variável } \\
2\end{array}$ & $\begin{array}{c}\text { Variável } \\
3\end{array}$ \\
\hline \multirow{3}{*}{ 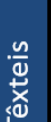 } & \multirow{3}{*}{$\begin{array}{c}\text { Variável } \\
1\end{array}$} & Opção 1 & Opção 1 & Opção 1 \\
\hline & & Opção 2 & Opção $\overline{2}$ & Opção $\overline{2}$ \\
\hline & & Opção 3 & Opçã̃o 3 & Opção 3 \\
\hline & \multirow{3}{*}{$\begin{array}{c}\text { Variável } \\
2\end{array}$} & Opção 1 & Opção 1 & Opção 1 \\
\hline .80 & & Opção 2 & Opçã̃o $\overline{2}$ & Opção $\overline{2}$ \\
\hline+ & & Opção 3 & $\overline{0} \overline{p c ̧ a ̃ o} \overline{3}$ & Opção 3 \\
\hline$\underset{\mathrm{u}}{\mathrm{u}}$ & \multirow{3}{*}{$\begin{array}{c}\text { Variável } \\
3\end{array}$} & Opção 1 & Opção 1 & Opção 1 \\
\hline$\frac{\sqrt{0}}{\frac{10}{2}}$ & & Opção 2 & Opção $\frac{2}{2}$ & Opção 2 \\
\hline & & Opção 3 & Ōpção $\overline{3}$ & Opção 3 \\
\hline
\end{tabular}

Fonte: Autoria própria (2017).

É importante ressaltar que, em vista da adição de um novo eixo, o que temos na prática são as opções $(1,2,3 \ldots n)$ sendo adicionados em uma terceira dimensão (matriz morfológica tridimensional), conforme a figura 4. 
Figura 4. Matriz morfológica tridimensional.
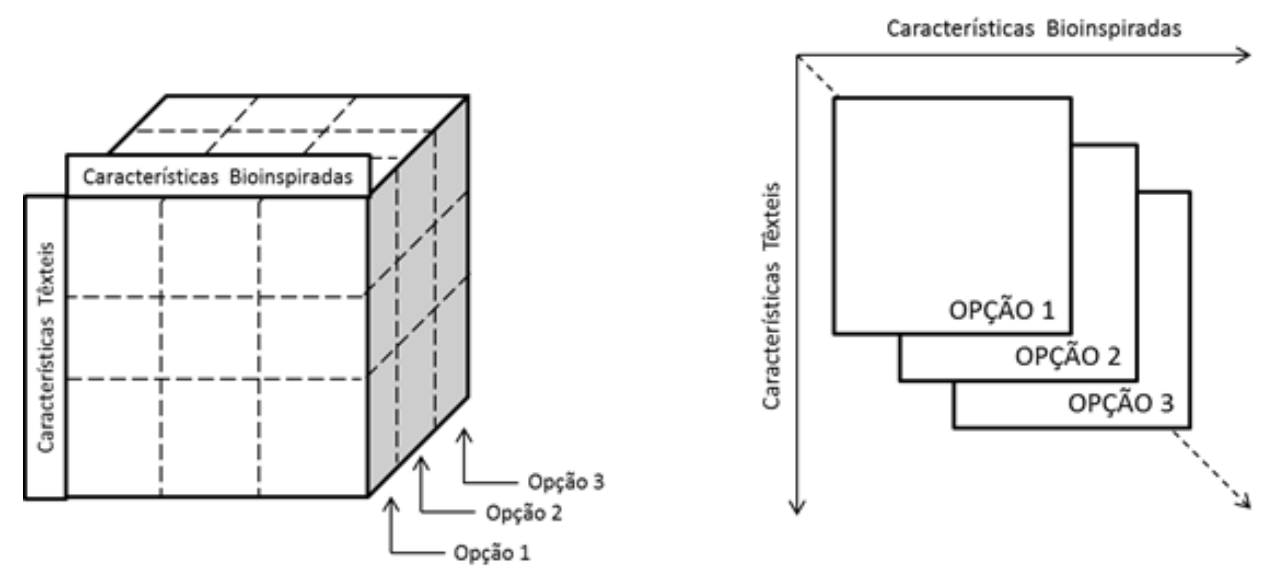

Fonte: Autoria própria (2017).

Contudo, para efeitos de simplificação visual - que é a proposta original da matriz morfológica optou-se pela utilização da matriz apresentada no quadro 1.

\section{CONCEPC̣ÃO DO MAIÔ FEMININO DE NATAC̣ÃO}

A matriz morfológica construída no Quadro 3 promove a combinação de elementos inspirados na biomimética dos tubarões e na tecnologia têxtil utilizada para desenvolver um maiô feminino para atividades aquáticas.

Segundo Rodrigues (2009) os tubarões pertencem à classe de peixes: cartilaginosos (Chondrichthyes) e a subclasse Elasmobranchii. Possuem alta mobilidade em meio aquático e são exímios predadores, exibindo convergência evolutiva em diversas características morfológicas e fisiológicas (BERNAL et al., 2001). A pele dos tubarões foi utilizada como modelo biomimético pelos pesquisadores por oferecer na estrutura superficial a redução ao arrasto da água e, consequentemente, o aumento da eficiência na locomoção (OEFFNER; LAUDER, 2012). 
Figura 5. Matriz morfológica para concepção de maiô de natação bioinspirado no tubarão

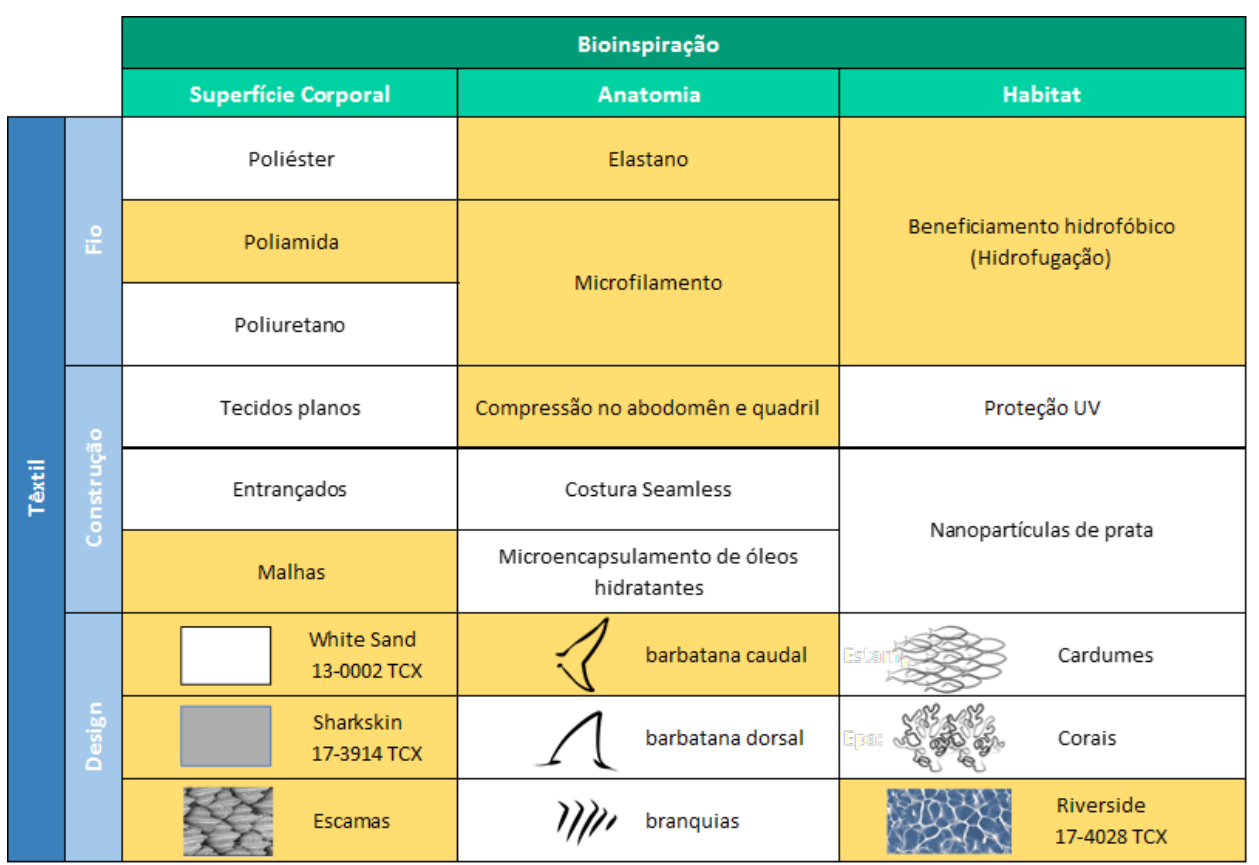

Fonte: Autoria própria (2017).

\subsection{Superfície Corporal}

As superfícies corporais dos tubarões são revestidas de escamas (denominadas escamas placóides) localizadas em toda a superfície do animal, elas auxiliam na execução dos movimentos (RODRIGUES, 2009). A empresa Speedo lançou os macacões Fastskin ${ }^{\circledR}$, nos quais as seções transversais dos fios foram inspiradas nas escamas placóides. Essa tecnologia permitiu reduzir o atrito e a turbulência da água resultando no aumento da velocidade do atleta (CRAIK, 2011).

Uma alternativa para obter essa capacidade hidrodinâmica é revestir o corpo do usuário com um têxtil sintético, pois eles possuem atributos hidrofóbicos, ou seja, baixa absorção da umidade, conferindo menos peso à peça quando utilizada. As fibras sintéticas também atuam como um revestimento de proteção resistente à fricção, dificultando o contato da água com a pele humana e fazendo com que ocorra menos turbulência ao entorno do usuário (CRUZ, 2012).

Segundo Shishoo (2005, p. 16) a fibra mais usada no vestuário esportivo é o poliéster, mas outras fibras como poliamida, poliuretano, acrílicas e o elastano são facilmente encontradas nas composições de tais peças. A maneira como os fios são dispostos no material identificam a estrutura na qual o têxtil será confeccionado, geralmente os mais usados são os tecidos planos, 
não-tecidos, entrançados e as malhas (DIAS, 2009). Na concepção do maiô foi selecionada a construção em malha, pois ela fornece maior mobilidade ao atleta. Segundo Cruz (2012) os tecidos de malha são usados para a prática esportiva desde o início do século XX.

Os peixes que geralmente vivem em mar aberto possuem uma coloração escura na sua superfície e no seu ventre cores claras, de maneira que ambas atuam como elemento adicional para confundir seus predadores. As cores escuras são misturadas com espectro de cores da água, quando observados por cima, e as cores claras se mesclam com a luz refletida do sol, quando observados de baixo (BEMVENUTI; FISCHER, 2010). Finalmente, a partir da aparência estética da superfície do tubarão foram elencadas as cores: branca (Pantone 13-0002 TCX White Sand), cinza (Pantone 17-3914 TCX Sharkskin) e a padronagem em escamas.

\subsection{Anatomia}

Para obter um melhor resultado anatômico podem ser realizadas combinações entres as fibras sintéticas para agregar características na confecção do tecido, que com apenas um tipo de fibra não seria possível. Por exemplo, na concepção do maiô optou-se por um fio misto de poliamida com elastano, sendo o elastano incorporado para fins anatômicos tendo em vista que adiciona uma propriedade elástica ao fio, fornecendo maior aderência ao corpo. Tanto a poliamida quanto o elastano, segundo Udale (2009, p. 50), oferecem conforto, resistência e secagem rápida. Conforme Cruz (2012), essa combinação é usada em trajes de banho desde a década de cinquenta. Segundo Gasi e Bittencourt (2010) as malhas confeccionadas em microfibras, fios com filamentos menores ou iguais a 1dtex, são muito usadas no mercado devido ao conforto e ajuste no corpo, essas características contribuem na aderência do maiô ao corpo impedindo a formação de bolhas de água entre a pele e o têxtil, reduzindo o atrito.

A velocidade dos peixes maiores, a partir de um metro, é superior quando comparada a dos peixes menores, isso é atribuído ao seu tamanho corporal e sua a inclinação mais ereta na execução do movimento (FLYNN; PEREIRA, 2015). Quanto melhor for a execução do movimento do usuário, mais eficiente será sua performance, assim é fundamental traduzir essa necessidade na montagem do maiô com um reforço na estrutura do quadril e abdômen. Essa compressão auxilia no desenvolvimento de um ângulo mais ereto em toda execução do movimento assim como acontece na hidrodinâmica dos peixes. Tais características, assim como uma costura seamless auxiliam em uma melhor hidrodinâmica. 
Tubarões, assim como peixes em geral, possuem diversas secreções e óleos considerados de grande importância no metabolismo desses animais, por exercerem funções biológicas específicas (VISENTAINER et al., 2000). O microencapsulamento de óleos hidratantes adicionados ao têxtil podem auxiliar os nadadores a diminuir os efeitos da excessiva exposição à água. Outros elementos da anatomia do tubarão foram listados na inspiração estética do maiô, como barbatanas (caudal e dorsal) e brânquias.

\subsection{Habitat}

A bioinspiração pode derivar do habitat do animal, isto é, o conjunto de fatores ambientais como temperatura, umidade, clima, tipo de solo, outras espécies bióticas, companheiros, alimentos, etc. Tubarões vivem predominantemente nas encostas, nas profundezas do oceano, nos estuários, nos rios e em mar aberto (RODRIGUES, 2009). O ambiente aquático inspirou a ideia de beneficiamento dos fios por meio de técnicas de hidrofugação (repelência à água) de modo a conferir ao tecido mais leveza e hidrodinâmica.

A maioria dos tubarões conhecidos nada em zonas epipelágicas e mesopelágicas do oceano, caracterizadas respectivamente por até 200 metros e de 200 até 1.000 metros de profundidade, e incidência de luz solar (GADIG, 2001), embora haja ainda muito a se explorar de zonas mais profundas do oceano. Em vista disso, foi elencada, como possibilidade, a adição de proteção UV à ideia do maiô, uma vez que a prática pode ocorrer em céu aberto. Nanopartículas de prata impregnadas no tecido também foram sugestionadas, em vista de sua reconhecida ação antimicrobiana e consequente combate a odores (DURÁN, 2007; NASCIMENTO et al., 2014).

Outros elementos do habitat natural dos tubarões foram utilizados como inspiração para o design da estampa, como os cardumes de peixe e os corais. O espectro de cores encontradas no oceano (WOOLF; SMITH, 2002) deu ensejo à seleção da cor azul escura (Pantone 17-4028 TCX Riverside) com o reflexo da água para a composição estética da peça. O modelo de maiô feminino proposto com a seleção de alguns elementos que compõem a matriz morfológica bioinspirada no tubarão é apresentado na figura 6 . 
Figura 6. Maiô feminino bioinspirado
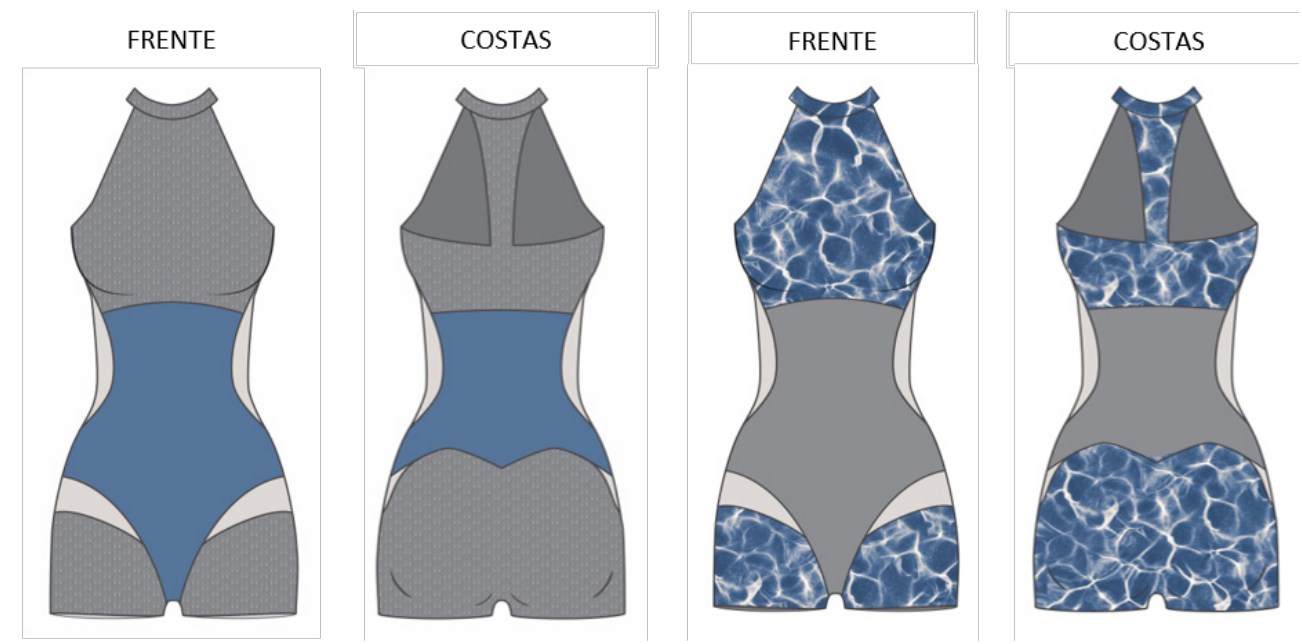

Fonte: Autoria própria (2017).

\section{CONCLUSÃO}

A etapa que antecede a geração de ideias para a concepção do produto é tão importante como a construção do produto em si. Reconhecer essa premissa permitiu que os pesquisadores desenvolvessem uma série de estudos que culminaram em técnicas sistemáticas para orientar essa fase essencial. Segundo Weber e Condoor (1998) essas técnicas se assemelham em razão de i) possibilitar a divisão das tarefas macros em tarefas micros, reduzindo assim o esforço cognitivo e aumentar a capacidade inovadora do designer, e ii) gerar várias soluções conceituais aumentando as possibilidades de soluções inovadoras.

Utilizar a matriz morfológica com a biomimética permite trazer para o desenvolvimento de produto, alternativas de design, como também modelos de soluções biológicas que os organismos vivos adaptaram ao longo dos 3,8 bilhões de anos. Contudo, a técnica proposta neste artigo não se limita apenas à utilização de bioinspiração. A matriz tridimensional pode ser combinada ainda com outros eixos temáticos de interesse tais como inspiração tecnológica, arquitetônica, literária e etc. 


\section{REFERÊNCIAS}

BEMVENUTI, Marlise de Azevedo; FISCHER, Luciano Gomes. Peixes: morfologia e adaptações. Cadernos de Ecologia Aquática, Rio Grande, v. 5, n. 2, p. 31-54, 2010.

BENYUS, Janine M. Biomimética: inovação inspirada pela natureza. São Paulo: Pensamento Cultrix, 2003.

BERNAL, Dolores; DICKSON, Kathryn A.; SHADWICK, Rebbeca; GRAHAM, Jeffrey B. Review: analysis of the evolutionary convergence for high performance swimming in lamnid sharks and tunas. Comparative Biochemistry and Physiology Part A: molecular \& integrative physiology, New York, v. 129, n. 2, p. 695-726, 2001.

CRAIK, Jennifer. The fastskin revolution: from human fish to swimming androids. Culture Unbound: journal of current cultural research, Linköping, v. 3, n. 1, p. 71-82, 2011.

CROSS, Nigel. Expertise in design: an overview. Design Studies, Oxford, v. 25, n. 5, p. 427-441, 2004.

CRUZ, Andreia da Silva. Desenvolvimento de fatos de banho para competição em natação pura. 2012. 178 f. Dissertação (Mestre em Design de Produto) Faculdade de Belas Artes, Universidade de Lisboa, Lisboa, 2012.

DIAS, Carolina Mónica Fernandes. Design de estruturas fibrosas híbridas para aplicação técnica. 2009. 105 f. Dissertação (Mestre em Engenharia Têxtil) Escola de Engenharia, Universidade do Minho, Braga, 2009.

DURÁN, Nelson et al. Antibacterial effect of silver nanoparticles produced by fungal process on textile fabrics and their effluent treatment. Journal of Biomedical Nanotechnology, Chengdu, v. 3, n. 2, p. 203-208, 2007.

FLYNN, Maurea Nicoletti; PEREIRA, William Roberto Luiz. Velocidade máxima de nado e possível desdobramento para o cálculo do tempo de resistência para peixes migratórios neotropicais. Revista Intertox de Toxicologia, Risco Ambiental e Sociedade, São Paulo, v. 6, n. 2, p. 19-31, 2015.

GADIG, Otto Bismarck Fazzano. Tubarões da costa brasileira. 2001. 360 f. Tese (Doutorado em Ciências Biológicas) - Universidade Estadual Paulista "Júlio de Mesquita Filho", Instituto de Biociências de Rio Claro, São Paulo, 2001. 
GASI, Fernando; BITTENCOURT, Edison. Estudo das propriedades de conforto em tecidos de malha das fibras sintéticas de poliéster e poliamida 6.6: permeabilidade ao vapor, transporte de umidade e proteção ultravioleta. Revista de Design, Inovação e Gestão Estratégica, Porto Alegre, v. 1, n. 1, p. 113126, 2010.

GESCHKA, Horst. Creativity techniques in product planning and development: a view from West Germany. R\&D Management, Oxford, v. 13, n. 3, p. 169, 1983.

HOEFNAGELS, Hild F.; WU, Deyong; WITH, G.; MING, Weihua. Biomimetic superhydrophobic and highly oleophobic cotton textiles. Langmuir, Washington, v. 23, n. 26, p. 13158-13163, 2007.

INTERNATIONAL ORGANIZATION FOR STANDARDIZATION. ISO 18458:2015: biomimetics - terminology, concepts and methodology. Genebra: ISO, 2015.

LOUREIRO, Danilo Roberto; FERNANDES, Haroldo Carlos; FURTADO JUNIOR, Marconi Ribeiro; SILVA, Anderson Candido; VALENTE, Domingos Sárvio Magalhães. Projeto conceitual do sistema de recolhimento de café para regiões montanhosas. In: SIMPÓSIO DE PESQUISA DOS CAFÉS DO BRASIL, 8., 2013, Salvador. Anais... Bahia: EMBRAPA, 2013.

NASCIMENTO, Joseheriberto Oliveira; MACIEL, Luciana Dantas Santos; ALMEIDA, Mariana Rodrigues; HOLANDA, Poincyana Sonaly Bessa; OLIVEIRA, Fernando Ribeiro. A Nanotecnologia aplicada ao produto de moda: criatividade e multifuncionalidade. 2 ㅇ Contexmod, São Paulo, v. 1, n. 2, p. 17, 2014.

OEFFNER, Johannes; LAUDER, George V. The hydrodynamic function of shark skin and two biomimetic applications. Journal of Experimental Biology, Cambridge, v. 215, n. 5, p. 785-795, 2012.

OSTERTAG, Oskar; OSTERTAGOVÁ, Eva; HUŇADY, Róbert. Morphological matrix applied within the design project of the manipulator frame. Procedia Engineering, Maryland Heights, v. 48, p. 495-499, 2012.

PAWLYN, Michael. Biomimicry in architecture. London: Riba Publishing, 2011.

PEREIRA, Priscila Zavaldi; SCHERER, Fabiano de Vargas; TEIXEIRA, Fábio Gonçalves; KOLTERMANN, Tânia; SILVA, Régio Pierre; CATTANI, Airton. Possibilidades de uso da matriz morfológica no processo de geração de alternativas em design. In: CONGRESSO BRASILEIRO DE PESQUISA E DESENVOLVIMENTO EM DESIGN, 4., 2014, São Paulo. Anais... São Paulo: Blucher Design Proceedings, 2014. v. 1, p. 1126-1135. 
PLENTZ, Samuel Sebben. Taxonomia para técnicas criativas aplicadas ao processo de projeto. 2011. 130 f. Dissertação (Mestre em Design) - Faculdade de Arquitetura, Universidade Federal do Rio Grande do Sul, Porto Alegre, 2011.

PODBORSCHI, Valeriu; VACULENCO, Maxim. Study of natural forms - the source of inspiration in product design. In: TALABA, Doru; ROCHE, Thomas (Ed.). Product engineering: eco-design, technologies and green energy. Netherlands: Springer, 2005. p. 111-120.

RITCHEY, Tom. Problem structuring using computer-aided morphological analysis. Journal of the Operational Research Society, Oxford, v. 57, n. 7, p. 792-801, 2006.

RODRIGUES, H. C. B. Dentículos dérmicos de tubarões da costa portuguesa: a sua utilização para identificação das diferentes espécies. 2009. 63 f. Dissertação (Mestrado em Ecologia Marinha) - Faculdade de Ciências, Universidade de Lisboa, Lisboa, 2009.

SARKAR, Manas; FAN, Juntu; SZETO, Yu-cheung; TAO, Xiaoming. Biomimetics of plant structure in textile fabrics for the improvement of water transport properties. Textile Research Journal, Lancaster, v. 79, n. 7, p. 657-668, 2009. SHISHOO, Roshan. Textiles in sport. North America: Woodhead Publishing Limited, 2005. v. 1.

TERRIER, Philippe; GLAUS, Mathias; RAUFFLET, Emmanuel. Biomimétisme: outils pour une démarche écoinnovante en ingénierie. Vertigo: la revue électronique en sciences de l'environnement, Montréal, 2017.

UDALE, Jenny. Fundamentos de design de moda: tecidos e moda. Porto Alegre: Bookman, 2009.

VANJIWALE, Swapnali R.; RAMAKRISHNAN, Reshma. Butterfly wings biomimicked in Textiles. The Bombay Technologist, Mumbai, v. 59, p. 30-32, 2009.

VISENTAINER, Jesuí Vergilio; CARVALHO; Patrícia de Oliveira; IKEGAKI, Masaharu; PARK, Young Kum. Concentração de ácido eicosapentaenóico (EPA) e ácido docosahexaenóico (DHA) em peixes marinhos da costa brasileira. Ciência e Tecnologia de Alimentos, Campinas, v. 20, n. 1, p. 90-93, 2000.

WEBER, Richard G.; CONDOOR, Sridhar S. Conceptual design using a synergistically compatible morphological matrix. In: FRONTIERS IN EDUCATION CONFERENCE, 28., 1998, Washington. Anais... Washington, 1998. p. 171-176.

WILLIAMS, John T. Textiles for cold weather apparel. North America: Woodhead Publishing Limited, 2009. v. 1. 
WOOLF, Neville J.; SMITH, Paul S. The spectrum of earthshine: a pale blue dot observed from the ground. The Astrophysical Journal, Bristol, v. 574, n. 1, p. 430-433, July 2002.

YANG, Maria C. Concept generation and sketching: correlations with design outcome. In: INTERNATIONAL DESIGN ENGINEERING TECHNICAL, CONFERENCES AND COMPUTERS AND INFORMATION IN ENGINEERING CONFERENCE, 2003, United States of America. Anais... Illinois: American Society of Mechanical Engineers, 2003. p. 829-834. 